\title{
Parallel Preoptic Pathways for Thermoregulation
}

\author{
Kyoko Yoshida, Xiaodong Li, Georgina Cano, Michael Lazarus, and Clifford B. Saper \\ Department of Neurology and Program in Neuroscience, Harvard Medical School, Beth Israel Deaconess Medical Center, Boston, Massachusetts 02215
}

Sympathetic premotor neurons in the rostral medullary raphe (RMR) regulate heat conservation by tail artery vasoconstriction and brown adipose tissue thermogenesis. These neurons are a critical relay in the pathway that increases body temperature. However, the origins of the inputs that activate the RMR during cold exposure have not been definitively identified. We investigated the afferents to the RMR that were activated during cold by examining Fos expression in retrogradely labeled neurons after injection of cholera toxin B subunit $(\mathrm{CTb})$ in the RMR. These experiments identified a cluster of Fos-positive neurons in the dorsomedial hypothalamic nucleus and dorsal hypothalamic area (DMH/DHA) with projections to the RMR that may mediate cold-induced elevation of body temperature. Also, neurons in the median preoptic nucleus (MnPO) and dorsolateral preoptic area (DLPO) and in the A7 noradrenergic cell group were retrogradely labeled but lacked Fos expression, suggesting that they may inhibit the RMR. To investigate whether individual or common preoptic neurons project to the RMR and DMH/DHA, we injected CTb into the RMR and Fluorogold into the DMH/DHA. We found that projections from the DLPO and MnPO to the RMR and DMH/DHA emerge from largely separate neuronal populations, indicating they may be differentially regulated. Combined cell-specific lesions of MnPO and DLPO, but not lesions of either one alone, caused baseline hyperthermia. Our data suggest that the MnPO and DLPO provide parallel inhibitory pathways that tonically inhibit the DMH/DHA and the RMR at baseline, and that hyperthermia requires the release of this inhibition from both nuclei.

\section{Introduction}

Many preoptic neurons respond to local brain, body core, and skin temperature (Hammel et al., 1960; Hayward and Baker, 1968; McEwen and Heath, 1974) but their role in regulating body temperature $(\mathrm{Tb})$ remains unknown. In rats, $\mathrm{Tb}$ is raised by the activation of interscapular brown adipose tissue (BAT) and tail artery vasoconstriction, which increase heat production and reduce heat loss, respectively. These sympathetically mediated responses are regulated by premotor neurons located in the rostral medullary raphe (RMR) (Morrison, 1999, 2004; Rathner and McAllen, 1999). Hyperpolarizing the RMR with muscimol prevents increases in $\mathrm{Tb}$ during both cold exposure and prostaglandin E2-induced fever (Morrison, 2003; Nakamura and Morrison, 2007; Ootsuka et al., 2008), suggesting that this region plays a key role in controlling sympathetic nerve discharge during elevation of $\mathrm{Tb}$.

Previous surveys of the afferent inputs to the RMR (Hosoya et al., 1987, 1989; Luppi et al., 1987; Hermann et al., 1997) have not determined those involved in thermoregulation. However inputs to the RMR from the median preoptic nucleus (MnPO) both contain GABA and express inhibitory EP3 prostaglandin recep-

Received June 5, 2009; revised Aug. 6, 2009; accepted Aug. 7, 2009.

This research was supported by United States Public Health Service Grant NS33987. We thank Dr. Issam Ayoub for producing some of the initial preoptic lesions and Quan Ha for her superb technical assistance.

Correspondence should be addressed to Dr. Clifford B. Saper, Department of Neurology, Beth Israel Deaconess Medical Center, 330 Brookline Avenue, Boston, MA 02215. E-mail: csaper@bidmc.harvard.edu.

X. Li's present addres: Department of Cell Biology, College of Life Sciences at Wuhan University, Wuhan, Hubei 430072, China

G. Cano's present address: Department of Neuroscience, University of Pittsburgh, A210 Langley Hall, Pittsburgh, PA 15260.

M. Lazarus' present address: Department of Molecular Behavioral Biology, Osaka Bioscience Institute, 6-2-4 Furuedai, Suita, Osaka 565-0874, Japan.

DOI:10.1523/JNEUROSCI.2643-09.2009

Copyright $\odot 2009$ Society for Neuroscience 0270-6474/09/2911954-11\$15.00/0 tors (Nakamura et al., 2002, 2009), which are required for fever responses to prostaglandin E2 (Lazarus et al., 2007). Thus, MnPO neurons may have a tonic inhibitory influence over RMR neurons that is reduced during fever. This view is supported by the elevation of baseline $\mathrm{Tb}$ and loss of fever responses after large lesions of the MnPO region (Romanovsky et al., 2003; Almeida et al., 2006).

Other studies have identified a dorsomedial preoptic site, in which neuronal inhibition by GABA agonists causes hyperthermia (Osaka, 2004) and in which GABA antagonists prevent hyperthermic responses elicited from the MnPO (Nakamura and Morrison, 2008a). Neurons at this site were thought to provide output to thermoregulatory effectors, but whether they project to the RMR is not known.

Neurons located at the border of the dorsomedial hypothalamic nucleus and dorsal hypothalamic area (DMH/DHA) also provide a major input to the RMR (Hosoya et al., 1987, 1989; Hermann et al., 1997). DMH/DHA neurons express Fos in response to systemic inflammation (DiMicco and Zaretsky, 2007), provide a critical relay in fever responses (Nakamura et al., 2005), and are necessary for thermogenic responses to skin cooling (Nakamura and Morrison, 2007). The DMH/DHA receives a major input from the MnPO (Saper and Levisohn, 1983; Simerly and Swanson, 1988), which appears to be necessary for thermogenesis evoked by prostaglandin E2 or skin cooling. However, it is unknown whether the DMH/DHA neurons that project to the RMR are activated during cold exposure.

We examined activation of neurons that project to the RMR during cold exposure by combining retrograde transport with immunolabeling for Fos. We also used retrograde double labeling to examine collateral projections to the RMR and DMH/DHA. We then dissected the relative roles of preoptic cell groups that 
project to the RMR in baseline thermoregulation and lipopolysaccharide (LPS)-induced fever by placing cell-specific lesions in those sites. Our results identify two parallel preoptic pathways for thermoregulation.

\section{Materials and Methods}

Animals

A total of 83 adult male Sprague Dawley rats (Harlan) were used in this study. Twenty-seven rats (323.1 $\pm 5.2 \mathrm{~g}$ body weight) were used for the tracing studies (Experiments 1A and 1B) and 45 rats (305.6 $\pm 5.1 \mathrm{~g}$ body weight) were used in the lesion studies (Experiment 2). All rats were housed individually in a pathogen-free animal facility, with ad libitum access to food and water, under a $12 \mathrm{~h}$ light-dark cycle (lights on at 7:00 A.M.) in a temperature-controlled environment $\left(21.5-22.5^{\circ} \mathrm{C}\right)$. The rats were monitored daily after surgery to assess general health and behavior. All procedures were in accordance with regulations detailed in the $\mathrm{Na}$ tional Institutes of Health Guide for the Care and Use of Laboratory Animals and were approved by the Institutional Animal Care and Use Committees of Beth Israel Deaconess Medical Center and Harvard Medical School.

\section{Surgery (injections and lesions)}

Experiment 1A: retrograde tracing from the RMR and Fos expression induced by cold exposure. Twenty rats were anesthetized with 7\% chloral hydrate $(350 \mathrm{mg} / \mathrm{kg}$, i.p.) and placed in a stereotaxic apparatus (Kopf Instruments). Following a midline incision of the scalp, a burr hole was made into the skull above the desired injection site. To identify putative afferents to the RMR, the retrograde tracer cholera toxin B subunit $(\mathrm{CTb})$ ( $1 \%$ in saline; List Biological Labs) was injected into the RMR using a glass micropipette (tip diameter $\sim 20 \mu \mathrm{m}$ ) and a compressed air delivery system. Small volumes $(3-6 \mathrm{nl})$ were delivered by directly measuring the displacement of the meniscus with a calibrated reticule on a surgery microscope. The coordinates for the RMR injections were: anteroposterior, $-11.5 \mathrm{~mm}$; dorsoventral (DV), $-9.6 \mathrm{~mm}$; right-left (RL), $0.0 \mathrm{~mm}$, obtained from the rat brain atlas by Paxinos and Watson (2005). The micropipette was left in place for an additional $2 \mathrm{~min}$ to minimize leakage and nonspecific labeling, and then withdrawn. The skull holes were filled with Surgifoam and the skin was closed with wound clips.

Simultaneously, Datalogger telemetry transmitters (SubCue Dataloggers) were implanted in 17 of these rats to measure core Tb. An incision was made in the abdomen and the device was implanted intraperitoneally. The abdominal wall was sutured and the skin closed with wound clips. The Dataloggers are small, reusable temperature recording devices encapsulated in biocompatible silicone. The recording schedule is programmed into the Datalogger before implantation, and the data are retrieved at the end of the experiment by removing the Datalogger postmortem and downloading the temperature readings to a computer (Boissé et al., 2004). The Dataloggers acquire a temperature recording every $5 \mathrm{~min}$.

After a 1 week recovery, $\mathrm{Tb}$ recordings started on the eighth day after surgery. Animals were habituated to a temperature-controlled chamber for $2 \mathrm{~h}$ per day (at 8:00 A.M.) during $7 \mathrm{~d}$, and then the next day they were exposed either to $3-4^{\circ} \mathrm{C}$ (cold exposure group, $n=8$ ) or room temperature $\left(24-25^{\circ} \mathrm{C}\right.$, control group, $\left.n=8\right)$ in the same chamber for $2 \mathrm{~h}$ at 8:00 A.M. After that, all rats were anesthetized with chloral hydrate (500 $\mathrm{mg} / \mathrm{kg}$ ) and killed by transcardiac perfusion.

The three remaining rats that did not have Dataloggers implanted but had CTb injections into the RMR were used to analyze whether some of the CTb retrogradely labeled neurons were dopaminergic or noradrenergic (double-fluorescence immunohistochemistry), as explained below.

Experiment 1B: dual retrograde tracing from the RMR and DMH/DHA. To investigate whether individual or common neurons project to both the RMR and the DMH/DHA, we injected CTb into the RMR and Fluorogold into the DMH/DHA, simultaneously into 8 rats. After injecting CTb into the RMR as detailed above, $6-9 \mathrm{nl}$ of Fluorogold (5\% in saline; Fluorochrome) were injected into the DMH/DHA area at coordinates: anteroposterior, $-3.48 \mathrm{~mm}$; DV,$-7.8 \mathrm{~mm}$; RL, $+0.5 \mathrm{~mm}$, from the rat brain atlas by Paxinos and Watson (2005). After each injection, the micropipette was left in place for an additional $2 \mathrm{~min}$ to minimize leakage

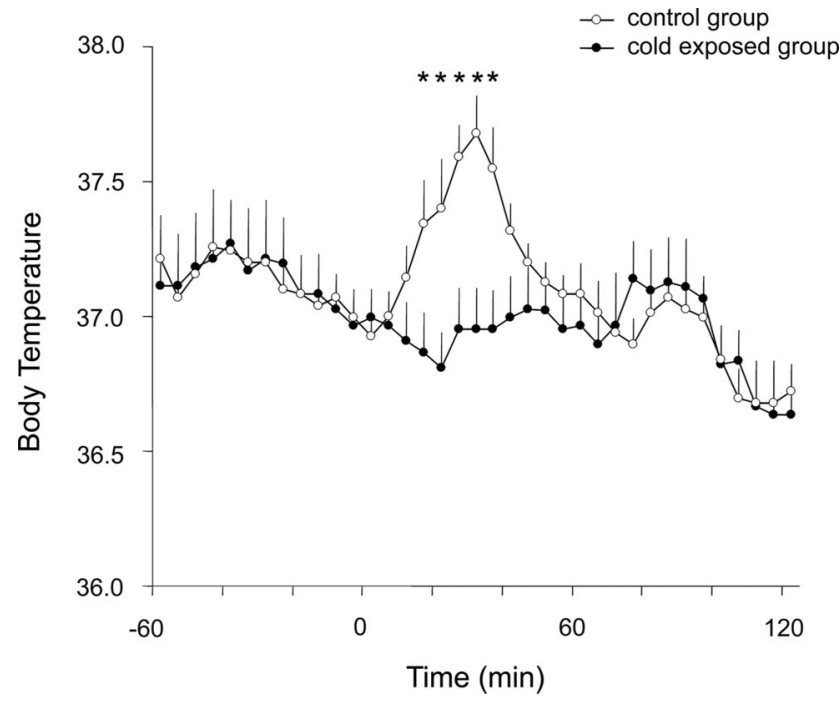

Figure 1. Changes in body temperature in cold-exposed rats (at $4^{\circ} \mathrm{C}, n=7$ ) compared with control rats (at $24^{\circ} \mathrm{C}, n=7$ ). Stress-induced hyperthermia was observed only in the control group at $15-45$ min after animals were transferred to the thermally controlled chamber at time 0 , but not in the cold-exposed group. Each point corresponds to the average temperature in a 5 min interval (12 points/h). Significant differences between groups are noted by asterisks ( $p<$ 0.05 ; repeated-measures ANOVA followed by paired $t$ tests for comparisons at each time point). All values are the mean \pm SEM.

and nonspecific labeling, and then withdrawn. The skull holes were filled with Surgifoam and the skin was closed with wound clips. After a 2 week recovery, animals were anesthetized with chloral hydrate $(500 \mathrm{mg} / \mathrm{kg})$ and killed by transcardiac perfusion.

Experiment 2: cell-specific lesions in the preoptic region. Rats were anesthetized with $7 \%$ chloral hydrate $(350 \mathrm{mg} / \mathrm{kg}$ body weight, i.p.), and placed in a stereotaxic apparatus for brain surgery. Following a midline incision of the scalp, a burr hole in the skull was made above the desired injection site. A glass micropipette containing 10\% ibotenic acid (SigmaAldrich) was lowered to the injection site, and animals were injected with 9-36 $\mathrm{nl}$ of ibotenic acid using the same system described above. Injections in the $\mathrm{MnPO}(n=23$; MnPO lesion group) were placed at coordinates: anteroposterior, $-0.1 \mathrm{~mm}$; DV,$-6.8 \mathrm{~mm}$; R, $0.0 \mathrm{~mm}$. Bilateral injections in the lateral preoptic area $(n=10$; DLPO lesion group) were placed at anteroposterior, $-0.8 \mathrm{~mm}$; DV,$-8.2 \mathrm{~mm}$; RL: $+0.6 \mathrm{~mm},-0.6$ $\mathrm{mm}$. In some cases $(n=12)$, we combined ibotenic acid injections at both sites simultaneously ( $\mathrm{MnPO}$ and DLPO). Control rats were injected with saline into these same areas ( $n=3$ controls for MnPO lesion, $n=3$ controls for DLPO lesion, $n=4$ controls for combined lesions). After injections, the micropipette was left in place for 2-3 min, slowly withdrawn, the skull holes were filled with Surgifoam, and the surgical site was closed with sterile wound clips. Immediately following these injections, a Datalogger telemetry transmitter was implanted in the peritoneal cavity of each rat as detailed above. After a 1 week recovery, rats were housed individually and were handled daily for $15 \mathrm{~min}$ (5-7 d) to minimize stress during the injection procedure. To assess baseline $\mathrm{Tb}$, recordings were done during $3 \mathrm{~d}$ with the Dattalogers. On the fourth day, each animal (all lesion groups and control groups) received an intraperitoneal injection of $10 \mu \mathrm{g} / \mathrm{kg}$ LPS (from Escherichia coli 055: B5, lot 044K4123, Sigma-Aldrich). Tb was recorded for $6 \mathrm{~h}$ after the injection (in $5 \mathrm{~min}$ data points). All injections were done at 10:00 A.M. to minimize the effect of circadian changes in $\mathrm{Tb}$. At the end of the $6 \mathrm{~h}$ postinoculation, rats were deeply anesthetized by an overdose of chloral hydrate $(500 \mathrm{mg} / \mathrm{kg})$ and perfused transcardially.

\section{Immunohistochemistry}

At the end of each experiment, rats were deeply anesthetized with chloral hydrate $(500 \mathrm{mg} / \mathrm{kg}$, i.p.) and transcardially perfused with $100-300 \mathrm{ml}$ of $0.9 \%$ saline followed by $500 \mathrm{ml}$ of $10 \%$ neutral phosphate-buffered formalin. Brains were removed, postfixed for $4 \mathrm{~h}$ in formalin, and cryo- 
protected overnight in $20 \%$ sucrose with $0.02 \%$ sodium azide (Sigma-Aldrich). Brains were then sectioned at $40 \mu \mathrm{m}$ into a 1:5 series on a freezing microtome.

Double immunohistochemistry for CTb + Fos, $\mathrm{CTb}+$ tyrosine hydroxylase $(\mathrm{TH})$, and $\mathrm{CTb}+$ Fluorogold were performed as described previously (Elmquist et al., 1998; Zhang et al., 2000; Yoshida et al., 2005; Lu et al., 2006). Briefly, for CTb + Fos double-labeling, after rinsing several times with $0.1 \mathrm{M} \mathrm{PBS,} \mathrm{pH}$ 7.4, for $1 \mathrm{~h}$, sections were incubated in $0.3 \%$ hydrogen peroxide in PBS containing $0.3 \%$ Triton X-100 (PBT), and washed again in PBS for $30 \mathrm{~min}$. Sections were incubated in the primary antiserum containing a rabbit Fos antibody (1:150K; Oncogene) in PBT for $24 \mathrm{~h}$ at room temperature. Sections were rinsed in PBS and incubated with biotinylated donkey antirabbit IgG (1:1000; Jackson ImmunoResearch) in PBT for $2 \mathrm{~h}$, rinsed 3 times in PBS, and incubated in avidin-biotin complex (Vectastain $\mathrm{ABC}$ Elite Kit; Vector Laboratories) for $1 \mathrm{~h}$. After several rinses in PBS, sections were incubated for 6-8 min in a combination of PBS, $1 \%$ diaminobenzidine tetrahydrochloride (DAB), $0.05 \%$ nickel ammonium sulfate, and $0.01 \%$ cobalt chloride, reacted with $0.01 \%$ hydrogen peroxide to obtain the chromogen reaction. The reaction was terminated with two rinses in PBS. With this procedure, a black nuclear precipitate for Fos-positive neurons was obtained.

After three $10 \mathrm{~min}$ rinses in PBS, tissue was incubated overnight in goat anti-CTb primary antiserum (1:2000; List Biological Labs). Sections were rinsed in PBS and then incubated for $2 \mathrm{~h}$ in $\mathrm{Cy} 3$-conjugated donkey anti-goat IgG (1:500; Jackson ImmunoResearch Laboratories), and rinsed in PBS for $1 \mathrm{~h}$. With this procedure, CTb-labeled neurons were visualized by their red fluorescent cytoplasm. Double-labeled neurons showed red fluorescent cytoplasm and a black Fos-positive nucleus.

For $\mathrm{CTb}+\mathrm{TH}$ double-labeling, sections were incubated in a mixture of primary antibodies: goat anti-CTb $(1: 2000)$ and mouse anti-TH (1:3000; ImmunoStar) overnight, and then rinsed in PBS and incubated for $2 \mathrm{~h}$ in a combination of Cy3-conjugated donkey anti-goat IgG (1:500) and Alexa-488 donkey anti-mouse IgG (1:500; Molecular Probes) to label $\mathrm{CTb}$-positive and TH-positive neurons with red (viewed with the Zeiss rhodamine filter set) and green (viewed with the Zeiss fluorescein filter set), respectively.

For CTb + Fluorogold double-labeling, sections were processed for $\mathrm{CTb}$ labeling with red fluorescence as detailed above and viewed with a Zeiss rhodamine filterset, and Fluorogold was visualized directly using a Zeiss UV fluorescent filter.

After the immunohistochemical procedures, all brain sections were mounted onto gelatin-coated glass slides, air-dried, dehydrated in alcohol, cleared in xylene, and coverslipped with Permaslip.

\section{Characterization of primary antibodies}

The affinity purified polyclonal Fos antibody used in this study (Ab5, Oncogene Science) was obtained from serum from rabbits immunized with a synthetic peptide (SGFNADYEASSSRC) corresponding to amino acids 4-17 of human c-Fos. Control sections were prepared by preadsorption of the antibody at $4^{\circ} \mathrm{C}$ with $0.1 \mathrm{mg} / \mathrm{ml} \mathrm{c}$-Fos peptide and showed no staining (manufacturer's technical information). The goat monoclonal anti-cholera toxin B subunit (703, lot \# 7032A4, List Biological Labs) was generated using the choleragenoid as antigen. This antibody produces a single band on a SDS-PAGE with cholera toxin B subunit (manufacturer's technical information). Immunostaining of sections from brains not injected with $\mathrm{CTb}$ does not produce any labeling. The mouse polyclonal anti-tyrosine hydroxylase (22941, lot \# 432001; ImmunoStar Inc.) was generated against TH isolated and purified from rat PC12 cells.
This antibody does not cross-react with dihydropteridine reductase, dopamine-B-hydroxylase, phenylethanolamine- $N$-methyltranferase, phenylalanine hydroxylase or tryptophan hydroxylase on Western blots (manufacturer's technical information). The pattern of cellular morphology and distribution stained in the hypothalamus was identical to that reported previously (Cechetto and Saper, 1988).

\section{Quantification of neurons and data analysis}

In all experiments, we examined the entire brain for Fos-, CTb-, and Fluorogold-immuno-

reactive neurons, and for double-labeled neurons (Fos/CTb, CTb/Fluorogold, and $\mathrm{CTb} / \mathrm{TH}$ ). In Experiment $1 \mathrm{~A}$, the location of $\mathrm{CTb}$ retrogradely labeled neurons after $\mathrm{CTb}$ injection into the RMR was described qualitatively and also mapped on drawings of coronal brain sections. The location of Fos-immunoreactive neurons after cold exposure was described qualitatively. In this same experiment, double-labeled neurons for $\mathrm{CTb}$ and Fos were counted in the DMH/DHA because it was the only brain region in which substantial numbers of double-labeled neurons were observed. The percentage of double-labeled neurons with respect to total CTb retrogradely labeled neurons in the DMH/DHA (CTb-Fos neurons/CTb-Fos neurons $+\mathrm{CTb}$ neurons) was compared between the two conditions (cold and room temperature) using a paired $t$ test $(p<$ 0.05).

In Experiment 1B, the location of double-labeled neurons after simultaneous CTb injection in the RMR and Fluorogold injection in the $\mathrm{DMH} / \mathrm{DHA}$ was described but not quantified because there were few if any double-labeled neurons in the brain.

In all cases, neurons were considered to be labeled only if there was a clear nucleus present.

Sections were photographed with a Cam HRc camera attached to an AxioPlan microscope, using AxioVision software (all from Zeiss). Contrast, brightness, and color balance of images was adjusted using Adobe Photoshop. In the figures, some photomicrographs were converted to gray scale. A copy of Figure 4 (red and green fluorescence image) (see below) was converted to magenta and green by using Adobe Photoshop and was included as supplemental Figure 1, available at www. jneurosci.org as supplemental material.

In Experiment 2, to determine the extent of neuronal loss in rat brains from all lesioned groups, we counted Nissl stained neurons with identifiable nuclei in rats with lesions in the MnPO, medial preoptic area 
A
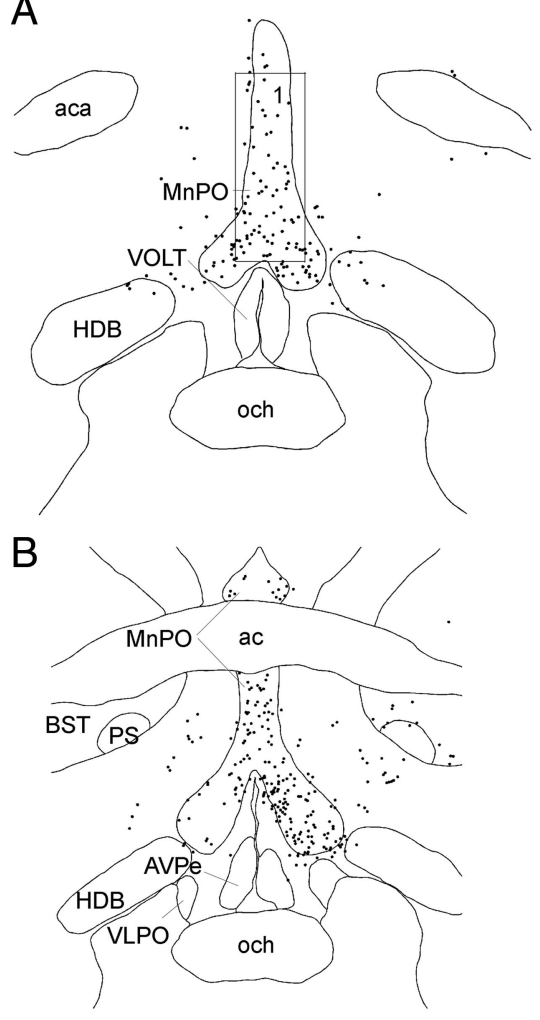

C

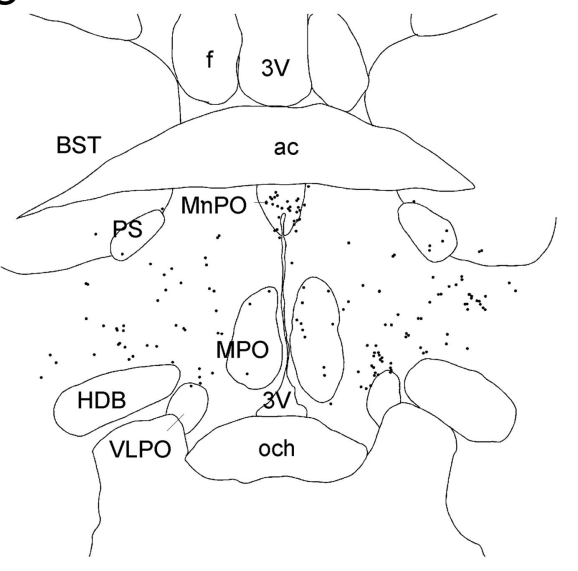

D

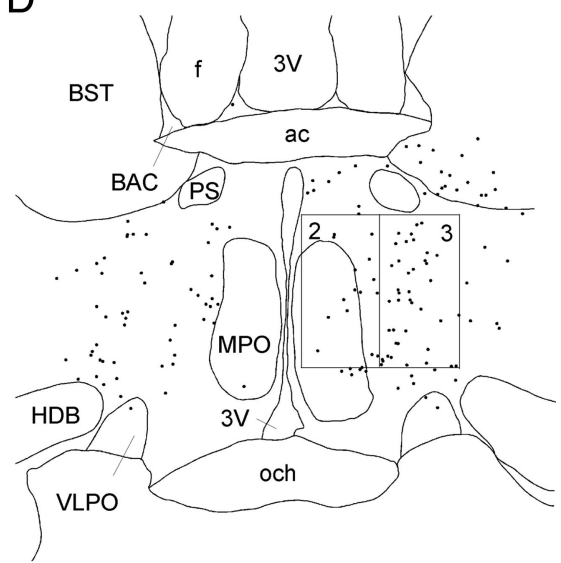

$\mathrm{E}$

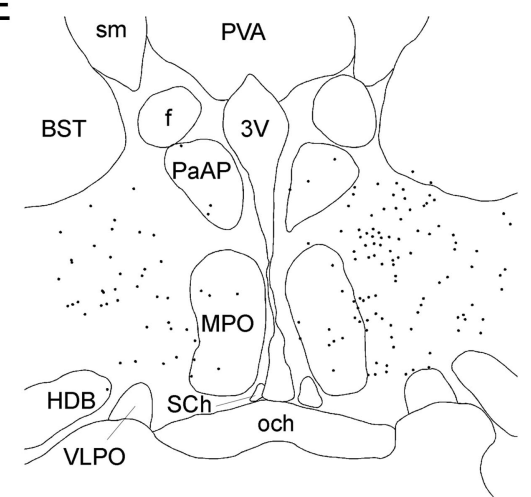

$\mathrm{F}$
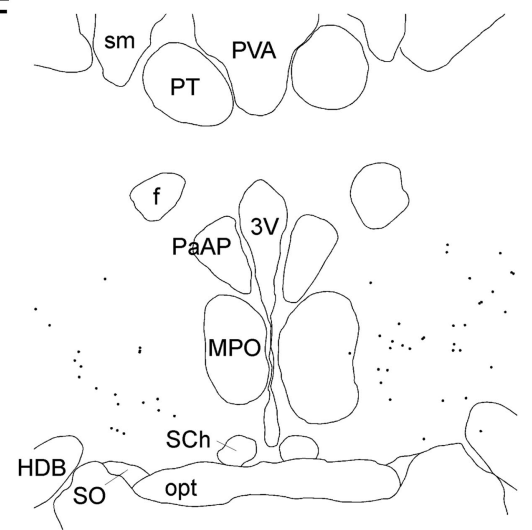

Figure 3. $A-F$, Drawings of brain sections from rostral to caudal levels of preoptic area after CTb injection into the RMR. Each dot represents one retrogradely labeled neuron. The counting box for the MnPO was placed dorsal to the opening of the third ventricle just rostral to the anterior commissure $(\boldsymbol{A}$, box 1$)$. Neurons in the medial preoptic area were counted by placing a box with the ventral border $300 \mu \mathrm{m}$ above the surface of the optic chiasm and its medial border along the wall of the third ventricle (D, box 2$)$ at the level of the bed nucleus of the anterior commissure of Gurdjian (BAC). For the DLP0, the counting box was placed just lateral to the medial preoptic box ( $\boldsymbol{D}$, box 3 ). $3 \mathrm{~V}$, Third ventricle; ac, anterior commissure; aca, anterior commissure, anteriot part; AVPe, anteroventral periventricular nucleus; f, fornix; HDB, nucleus of the horizontal limb of the diagonal band; och, optic chiasm; opt, optic tract; PaAP, paraventricular hypothalamic nucleus, anterior parvicellular part; PS, parastrial nucleus; PT, paratenial thalamic nucleus; $\mathrm{PVA}$, paraventricular thalamic, anterior part; $\mathrm{SCh}$, suprachiasmatic nucleus; sm, stria medullaris of the thalamus; SO, supraoptic nucleus; VLPO, ventrolateral preoptic nucleus; VOLT, vascular organ of the lamina terminalis.

(MPA), and DLPO. Nissl stained neurons were counted in a $400 \mu \mathrm{m} \times$ $1000 \mu \mathrm{m}$ box placed dorsal to the third ventricle (see Fig. $3 A$, box 1 ) to count neurons in the MnPO. Neurons in the MPA were counted by placing a $400 \mu \mathrm{m} \times 800 \mu \mathrm{m}$ box ventral border $300 \mu \mathrm{m}$ above the surface of the optic chiasm and its border along the third ventricle (see Fig. 3D, box 2). For DLPO, the counting box $(400 \mu \mathrm{m} \times 800 \mu \mathrm{m})$ was placed just lateral to the MPA box (see Fig. $3 D$, box 3 ). In each case, we only counted neurons that had a clearly defined nucleus. The nuclear diameter was measured in a sample of 10 neurons from each group, and then the cell counts were corrected for nuclear size by using the Abercrombie correction factor (Guillery, 2002).

To determine the contribution of each of the preoptic sites to the hyperthermic responses observed after some cell-specific lesions, we assessed the correlation between the number of remaining neurons and $\mathrm{Tb}$, by performing a Pearson correlation analysis for each combined lesion $(p<0.05)$. This analysis allowed us to examine whether there was a linear relationship between the differences in baseline $\mathrm{Tb}$ and the number of remaining cells in each lesion site.

\section{Temperature analysis}

In Experiment $1 \mathrm{~A}$, the baseline $\mathrm{Tb}$ was recorded for $24 \mathrm{~h}$ before animals were transferred into the chamber and the average temperature of rats in each group (control and cold exposed rats) were compared using a paired $t$ test ( $p<$ $0.05)$. During the experimental day, Tb recordings were analyzed from 7.00AM to $10.00 \mathrm{AM}$. Differences in $\mathrm{Tb}$ between the two groups due to the treatment (cold vs room temperature) were compared using a repeated-measures ANOVA followed by paired $t$ tests for comparisons at each time point $(p<0.05)$ along the $2 \mathrm{~h}$ interval from 8.00AM (transfer to the chamber) to 10.00AM (end of the experiment).

In Experiment 2, the baseline $\mathrm{Tb}$ of all rats (lesioned and controls) was recorded and plotted along the $3 \mathrm{~d}$. The daily average $\mathrm{Tb}$ in each lesioned group vs each control group was compared using a paired $t$ test for each lesioned group (MnPO, DLPO, combined lesions; $p<$ $0.05)$. On the injection day, $\mathrm{Tb}$ recordings were analyzed in a $7 \mathrm{~h}$ interval from 9:00 A.M. (LPS injection at 10:00 A.M.) to 4:00 P.M. (end of experiment) in all rats. LPS-induced changes in temperature between each lesion group (MnPO, DLPO, and combined lesions) were compared with the control group. These comparisons were done using a repeated-measures ANOVA followed by paired $t$ tests for comparisons at each time point $(p<0.05)$ along the $7 \mathrm{~h}$ interval.

\section{Results}

\section{Experiment $1 \mathrm{~A}$}

Changes in $\mathrm{Tb}$ during cold exposure

The average baseline $\mathrm{Tb}$ did not differ significantly between the two groups $(37.1 \pm$ 0.1 and $37.0 \pm 0.1$ for control and cold exposed rats, respectively; paired $t$ test, $p=0.12$. Figure 1 shows the $\mathrm{Tb}$ on the experimental day, which was quite similar in the two groups in the hour previous to transferring them to the chamber. At 8:00 A.M. (Fig. 1, time 0 ) on this day, rats were transferred to the thermally controlled chamber at $24-25^{\circ} \mathrm{C}$ (control group, $n=7$ ) or at $3-4 \mathrm{C}^{\circ}$ (cold-exposed group, $n=7$ ) for $2 \mathrm{~h}$. As shown in Figure 1, control rats showed a moderate increase in $\mathrm{Tb}(\sim 0.6-$ $0.7^{\circ} \mathrm{C}$ ) lasting $\sim 45 \mathrm{~min}$ after they were placed into the thermally controlled chamber maintained at room temperature. This small 
elevation in $\mathrm{Tb}$ is a typical hyperthermic response induced by stress, which is observed whenever rats are handled or placed in a new environment. In contrast, cold-exposed rats did not show this $\mathrm{Tb}$ elevation during the first $45 \mathrm{~min}$ after exposure, but their temperature instead remained at its baseline. After $45 \mathrm{~min}$, the $\mathrm{Tb}$ did not differ between the two groups, demonstrating an appropriate thermoregulatory response during cold (in the cold-exposed group), and a transient effect of handling-evoked hyperthermia (in the control group).

\section{Retrograde tracing from the $R M R$}

Seventeen rats were implanted with Dataloggers and had injections of CTb targeted in the RMR. The injections included at least part of the raphe pallidus nucleus in 14 of these animals (Fig. $2 B-D$ ), but in nearly all of these cases, the injections also tracked dorsally to include parts of the raphe magus nucleus (RMg), as shown in a characteristic case illustrated in Figure 2A. Nason and Mason (Nason and Mason, 2006) have argued that the responses of the raphe pallidus nucleus neurons to both $\mathrm{Tb}$ changes and pain are similar to neurons in the adjacent raphe magnus nucleus (RMg) and that injections of GABA agonists into the raphe pallidus nucleus that blocked thermogenic responses may have also involved leakage of the drugs into the RMg. Anterograde tracer experiments (Simerly and Swanson, 1988; Thompson et al., 1996) also indicate that the projections from the $\mathrm{MnPO}$ and the DMH/DHA include both the raphe pallidus nucleus and RMg. Thus, we refer to this entire group of injections as being in the RMR. These injections in many cases also spread to some degree into the adjacent paramedian medullary reticular formation. However, this additional involvement was generally asymmetric, and by comparing these with cases that did not include the reticular formation, we could identify the populations of neurons that were retrogradely labeled from the medullary raphe nuclei.

The distribution of retrogradely labeled (CTb-immunoreactive) neurons after these injections in a representative rat is illustrated in Figures 3 and 4. A large number of retrogradely labeled neurons were found bilaterally in the $\mathrm{MnPO}$ (Fig. $3 A-C)$. Neurons in this cluster extended ventrolaterally beyond the borders of the $\mathrm{MnPO}$ as recognized in Nissl-stained sections, as far ventrally as the dorsal border of the ventrolateral preoptic nucleus (Fig. 3B). A second population of retrogradely labeled neurons, quite distinct from the $\mathrm{MnPO}$, was seen centered just caudal and lateral to
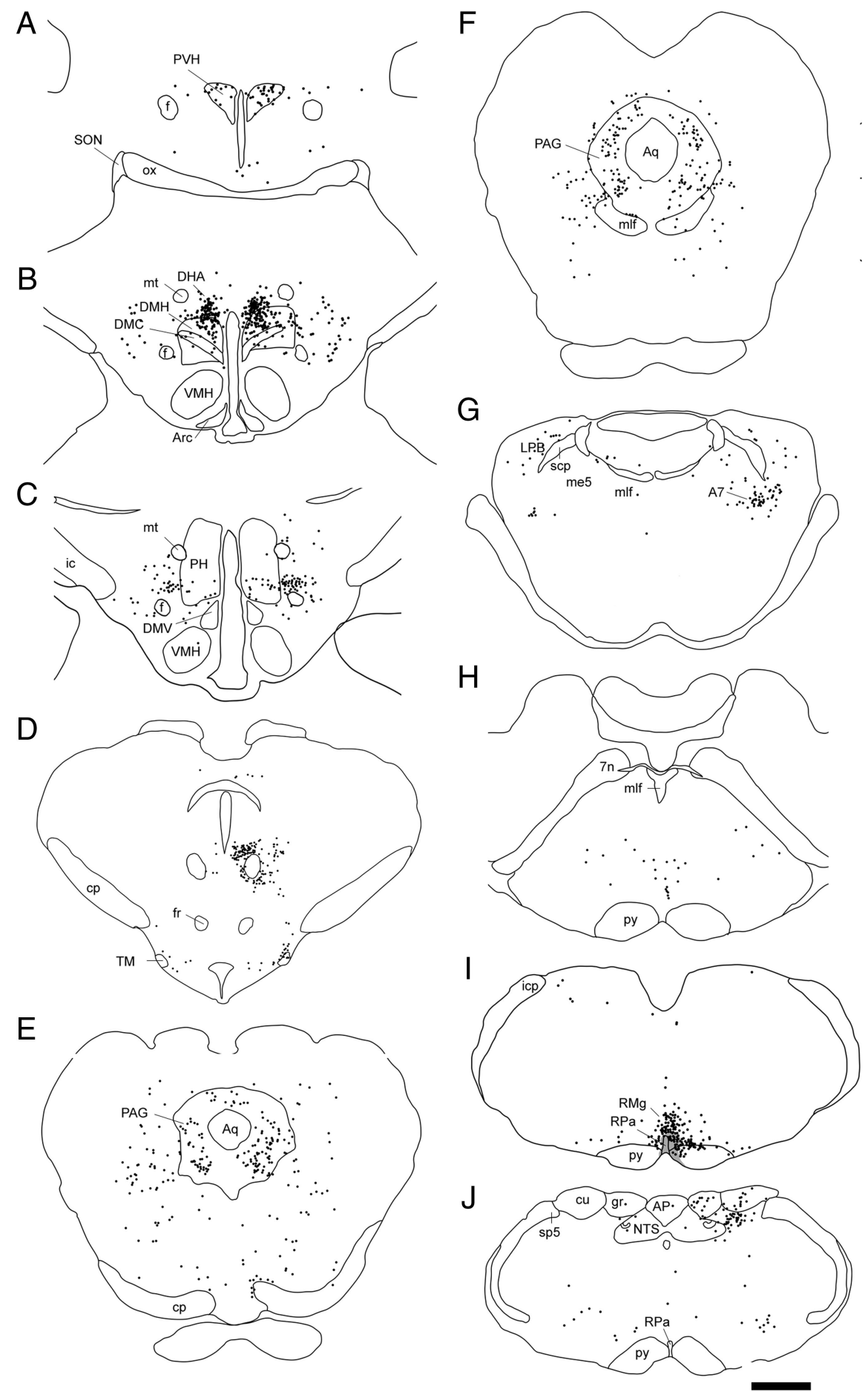

Figure 4. $A-J$, Drawings of brain sections from the paraventricular hypothalamic nucleus $(\boldsymbol{A})$ to the medulla $(\boldsymbol{J})$ after $(\mathrm{Tb}$ injection into the RMR (injection site is shown by shading in $I$ ). Each dot represents one retrogradely labeled neuron. Scale bar, 1 $\mathrm{mm}$. 7n, Facial nerve; A7, A7 noradrenergic cell group; AP, area postrema; Aq, cerebral aqueduct; Arc, arcuate nucleus; $c p$, cerebral peduncle, basal part; cu, cuneate fasciculus; DMC, dorsomedial hypothalamic nucleus, compact part; DMV, dorsomedial hypothalamic nucleus, ventral part; $f$, fornix; fr, fasciculus retroflexus; gr, gracile fasciculus; ic, internal capsule; icp, inferior cerebellar peduncle; LPB, lateral parabrachial nucleus; me5, mesencephalic trigeminal tract; mlf, medial longitudinal fasciculus; $\mathrm{mt}$, mammillothalamic tract; NTS, nucleus of the solitary tract; ox, optic chiasm; PH, posterior hypothalamic area; PS, parastrial nucleus; $p y$, pyramidal tract; RMg, raphe magnus nucleus; Rpa, raphe pallidus nucleus; scp, superior cerebellar peduncle; SON, supraoptic nucleus; sp5, spinal trigeminal tract; TM, tuberomammillary nucleus; $\mathrm{VMH}$, ventromedial hypothalamic nucleus.

the medial preoptic nucleus (Fig. 3C-E). This latter neuronal group was more diffusely organized than the MnPO group, spreading from $\sim 0.4-2.0 \mathrm{~mm}$ lateral to the wall of the third ventricle, and dorsoventrally from about the dorsal edge of the 

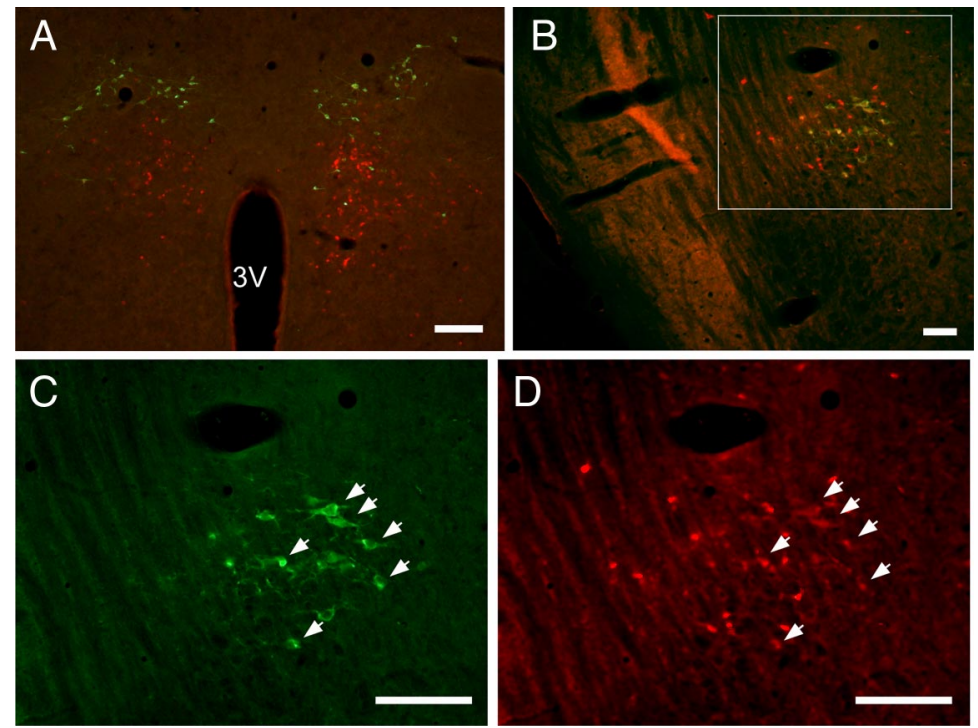

Figure 5. $A-D, A$ series of photomicrographs illustrating tyroxine hydroxylase (TH)-immunoreactivity (green) and $\mathrm{CTb}$ immunoreactivity (red) in the DMH/DHA cell areaA11/A13 dopaminergic group $(\boldsymbol{A})$, and the rostral pontine cell group that includes the $A 7$ noradrenergic group $(\boldsymbol{B}-\boldsymbol{D})$, after injection of CTb into the RMR. Both areas project to the medullary raphe but only $A 7$ noradrenergic neurons were double-labeled. A11/A13 dopaminergic neurons are located dorsally to the DMH/DHA neurons that project to the medullary raphe (CTb-labeled neurons). Photomicrographs $\boldsymbol{C}$ and $\boldsymbol{D}$ are higher-magnification images of the area indicated by the box in $\boldsymbol{B}$. Arrows point to doubly labeled neurons (A7 noradrenergic cells that project to the RMR). Scale bars: $\boldsymbol{A}, 200 \mu \mathrm{m} ; \boldsymbol{B}-\boldsymbol{D}, 100 \mu \mathrm{m}$. 3V, Third ventricle. For color-blind readers, a copy of this figure with the red fluorescence converted to magenta is included as supplemental Figure 1, available at www.jneurosci.org as supplemental material.

A

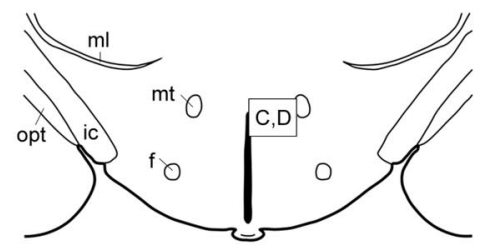

Bregma $-3.36 \mathrm{~mm}$
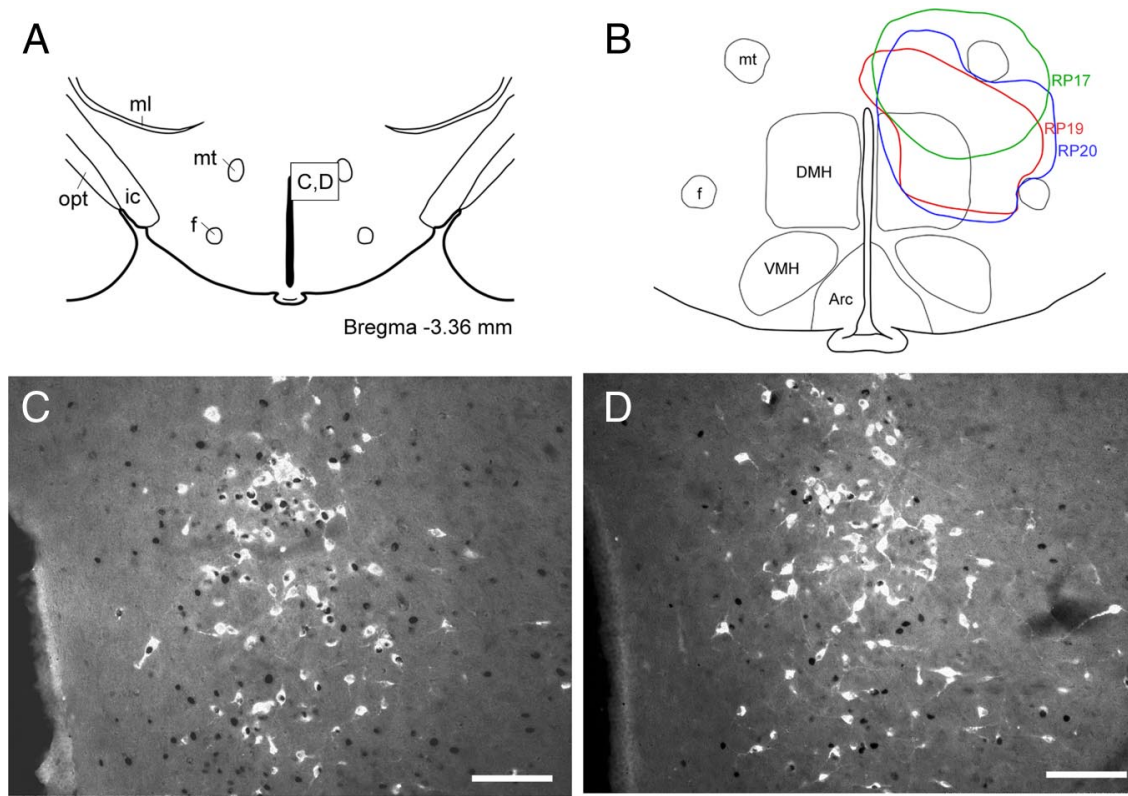

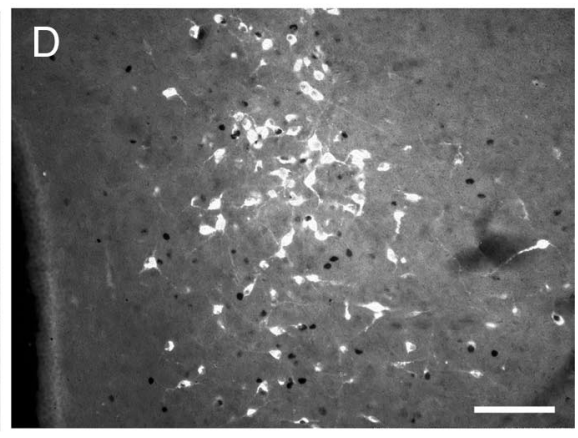

Figure 6. Cold exposure induces Fos expression in DMH/DHA neurons that project to the RMR. The diagram in $\boldsymbol{A}$ shows the location of the DMH/DHA (box), which contained numerous retrogradely labeled neurons after CTb injection into the RMR. Photomicrographs in $\boldsymbol{C}$ and $\boldsymbol{D}$ show the distribution of doubly labeled neurons for Fos (black nucleus) and CTb (retrogradely labeled white cytoplasm) after exposure to cold $\left(3-4^{\circ} \mathrm{C}\right)(\boldsymbol{C})$ or room temperature $\left(24-5^{\circ} \mathrm{C}(\boldsymbol{D})\right.$. There were many more doubly labeled neurons after exposure to cold $(\boldsymbol{C})$ than to room temperature $(\boldsymbol{D})$. The line drawing in $\boldsymbol{B}$ shows the injection sites of Fluorogold in the same DMH/DHA area. The green line indicates the injection in case RP17, the red line in case RP19, and the blue line in case RP20. Scale bars: $\boldsymbol{B}, \boldsymbol{C}, 100 \mu \mathrm{m}$. 3V, Third ventricle; Arc, arcuate nucleus; DMH, dorsomedial hypothalamic nucleus; f, fornix; ic, internal capsule; ml, medial lemniscus; mt, mammillothalamic tract; opt, optic tract; VMH, ventromedial hypothalamic nucleus.

ventrolateral preoptic nucleus to the ventral edge of the parastrial nucleus and bed nucleus of the stria terminalis (although a few retrogradely labeled neurons spilled over into these cell groups). These neurons were found from about the midpoint of the crossing of the anterior commissure [about the bregma -0.1 level in Paxinos and Watson (2005) to a level just caudal to the foramen of Monro (bregma -0.6)]. This cell group does not coincide with any previously described entity we are aware of, but because it is generally located lateral to the medial preoptic nucleus and dorsal to the ventrolateral preoptic nucleus, we have termed this neuronal group the dorsolateral preoptic area (DLPO).

At the level of the paraventricular hypothalamic nucleus $(\mathrm{PVH})$, retrogradely labeled neurons were observed predominantly in its dorsal and ventral parvicellular subdivisions (Fig. $4 A$ ), which provide autonomic regulatory projections to the medulla and the spinal cord (Saper et al., 1976; Sawchenko and Swanson, 1982). A small region of intense retrograde staining was found in the DMH/DHA at the level of the compact part of the DMH (at $-3.48 \mathrm{~mm}$ from bregma; Paxinos and Watson, 2005) (Fig. 4B). This cell group is best observed in coronal sections at the level where the ventral surface of the mammillothalamic tract is just even with the dorsal tip of the third ventricle, and consists of a dense neuronal cluster along the dorsal margin of the DMH. A more diffuse group of retrogradely labeled neurons was also seen dispersed in the $\mathrm{DMH}$. Retrogradely labeled neurons were also found in the perifornical area at the level of the posterior hypothalamic area (PH) (Fig. 4C). At the level of the midbrain, retrogradely labeled neurons were observed in the rostral part of the periaqueductal gray matter (PAG) (Fig. 4D,E). Retrogradely labeled neurons at the caudal midbrain level were also seen in the ventrolateral, lateral, dorsolateral, and dorsomedial PAG, but not in the dorsal raphe nucleus (Fig. 4F). Another cluster of retrogradely labeled neurons was observed in the rostral pontine reticular formation, just medial to the lateral lemniscus, and ventral to the rostral pole of the parabrachial nucleus, in the region of the A7 noradrenergic cell group (Fig. $4 G$ ). An additional cluster of retrogradely labeled neurons was centered in the ventrolateral part of the nucleus of the solitary tract (Fig. 4J).

\section{Cathecholaminergic projections to \\ the RMR}

Because of the proximity of the retrogradely labeled neurons in the DMH/ DHA to the A11/A13 dopamineric cell group, and the retrogradely labeled neurons in the pons to the A7 noradrenergic cell group, we performed double-fluorescence immunohistochemistry for $\mathrm{CTb}$ (retrograde labeling from the RMR) and TH (to identify catecholaminergic neurons) to determine whether the neurons that 
project to the RMR are indeed catecholaminergic. For this experiment, 3 rats were injected with CTb into the RMR (no Dataloggers implanted); the injections all involved the RMR as well as the overlying raphe magnus nucleus. None of the $\mathrm{CTb}-$ immunoreactive neurons in the $\mathrm{DMH} /$ DHA group were doubly labeled (Fig. 5A). However, approximately half of the neurons in the rostral pontine cell group that projects to the RMR were also immunoreactive for $\mathrm{TH}$, indicating that they are part of the A7 noradrenergic cell group (Fig. $5 B-D)$. Other noradrenergic groups in the brainstem were examined and none of them contained doubly labeled neurons. Therefore, the only source of noradrenergic input to the RMR appears to be the A7 group.

\section{Cold-induced Fos immunoreactivity}

The distribution of Fos expression induced by cold was similar to that previously described (Kiyohara et al., 1995; McKitrick, 2000; Cano et al., 2003; Bratincsák and Palkovits, 2004; Yoshida et al., 2005), and included neurons in the dorsal part of the lateral septum, the bed nucleus of the stria teminalis (BST), the MnPO, the ventromedial and ventrolateral preoptic areas, the PVH, the paraventricular thalamic nucleus, the arcuate nucleus, the supramammillary nucleus, the cingulate and piriform cortexes, the dorsal raphe nucleus, and the external lateral parabrachial subnucleus. In addition, we also observed cold-induced Fos immunoreactivity in the anteroventral periventricular nucleus, the parastrial nucleus, the central amygadaloid nucleus, the DMH/DHA, the zona incerta, the lateral hypothalamus, the posterior hypothalamus, the parasubthalamic nucleus, the PAG, the pedunculopontine tegmental nucleus, the dorsal tegmental nucleus, the RMR, and the nucleus of the solitary tract.

\section{Distribution of neurons that project to the $R M R$ and are activated} by cold exposure (Fos-immunoreactive)

In the present study, although several areas contained both retrogradely labeled neurons and Fos-immunoreactive neurons after cold exposure, we could find substantial numbers of doubly labeled neurons only in the DMH/DHA area, at the level in which the ventral border of the mammillothalamic tract is aligned with the dorsal edge of the third ventricle (Fig. 6). There were three times more doubly labeled neurons in the DMH/DHA of coldexposed rats compared with controls exposed to room temperature $(59.6 \pm 2.6 \%$ vs $17.9 \pm 2.2 \%$, respectively; $p<0.001)$. In particular, the double labeling in the dense cluster of neurons just dorsal to the DMH stood out. In contrast, the large numbers of $\mathrm{CTb}$-immunoreactive neurons located in the MnPO and DLPO were conspicuous for their lack of double labeling. Lack of Fosimmunoreactivity in these cell groups would be expected if they inhibit elevation of Tb. However, recent studies by Nakamura and
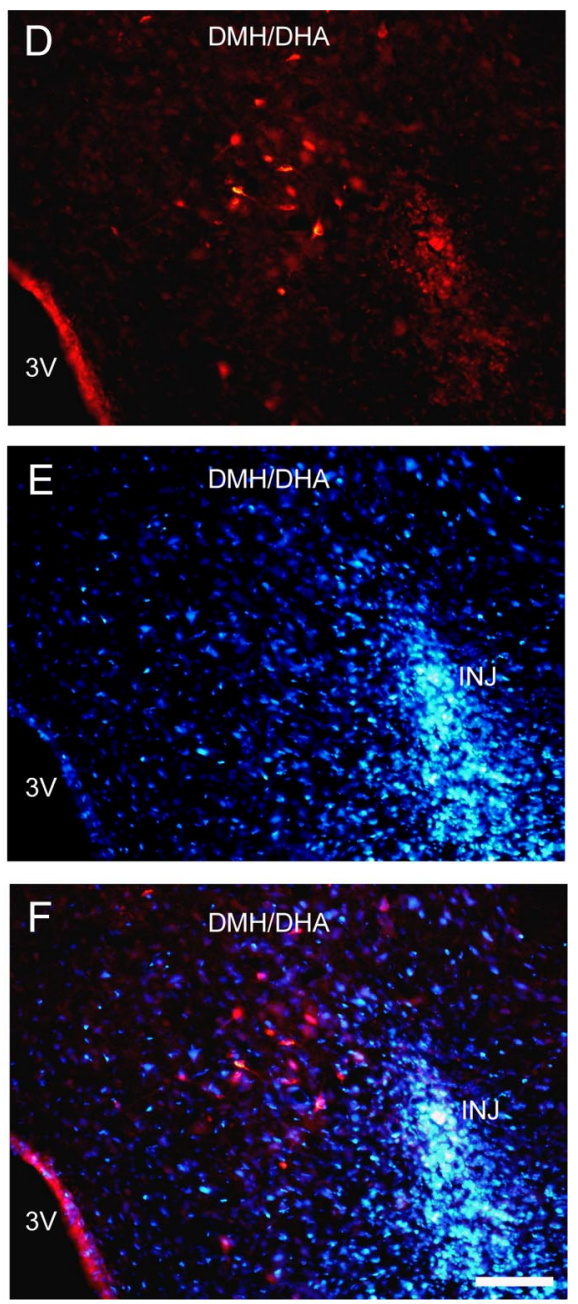

Figure 7. Neurons in the MnPO that project to the RMR do not project simultaneously to the DMH/DHA. Photomicrographs in

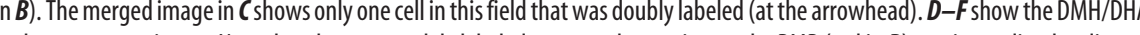
mage has been reduced in this set of photographs to avoid oversaturating the images; tracer spreads in all directions at least 500 $\mu \mathrm{m}$ from the center of the injection as shown in Figure $6 B$, experiment RP20. Scale bar, $100 \mu \mathrm{m}$. 3V, Third ventricle; INJ, Fluorogold injection site; OVLT, organum vasculosum of the lamina terminalis.

Morrison (2008b) suggest that activation of some MnPO neurons may play an important role in cold-defensive responses. If so, these neurons would either not project to the RMR, or would not produce Fos when activated.

\section{Experiment 1B: simultaneous retrograde tracing from the} RMR and the DMH/DHA

To determine whether neurons that project to the RMR also project to the DMH/DHA, a second key site in hyperthermic responses, we next injected $\mathrm{CTb}$ into the RMR and Fluorogold into the DMH/DHA area in 8 rats. The injections hit both targets in 3 animals. Large numbers of both Fluorogold (Fig. 7B) and $\mathrm{CTb}$ (Fig. 7A) retrogradely labeled neurons were found in the $\mathrm{MnPO}$ and in the DLPO, but only a few of these neurons were doubly labeled (Fig. 7C). Thus, the projections from the two preoptic sites, DLPO and MnPO, to the RMR and the DMH/ DHA appear to emerge from almost entirely separate populations of neurons, indicating that they may be differentially regulated. 
Table 1. Lesions of the MnPO and DLPO, but not of individual nuclei that are part of the preoptic area, caused a profound increase in Tb compared with unlesioned controls

\begin{tabular}{lll}
\hline Measurement & MnPO + DLPO lesions versus control & MnPO lesions versus control \\
\hline Number of rats & 6 versus 4 & 8 versus 3 \\
Body temperature & $38.2 \pm 0.1$ versus $37.3 \pm 0.2$ & $67.2 \pm 0.05$ versus $37.3 \pm 0.3$ \\
$t$ test, $p$ value & $0.0052^{*}$ & 0.53 \\
\hline
\end{tabular}

Tb in each group was averaged over $3 \mathrm{~d}$. Tb in unlesioned controls was compared with that in each lesion group using an unpaired $t$ test $\left({ }^{*} p<0.01\right)$.
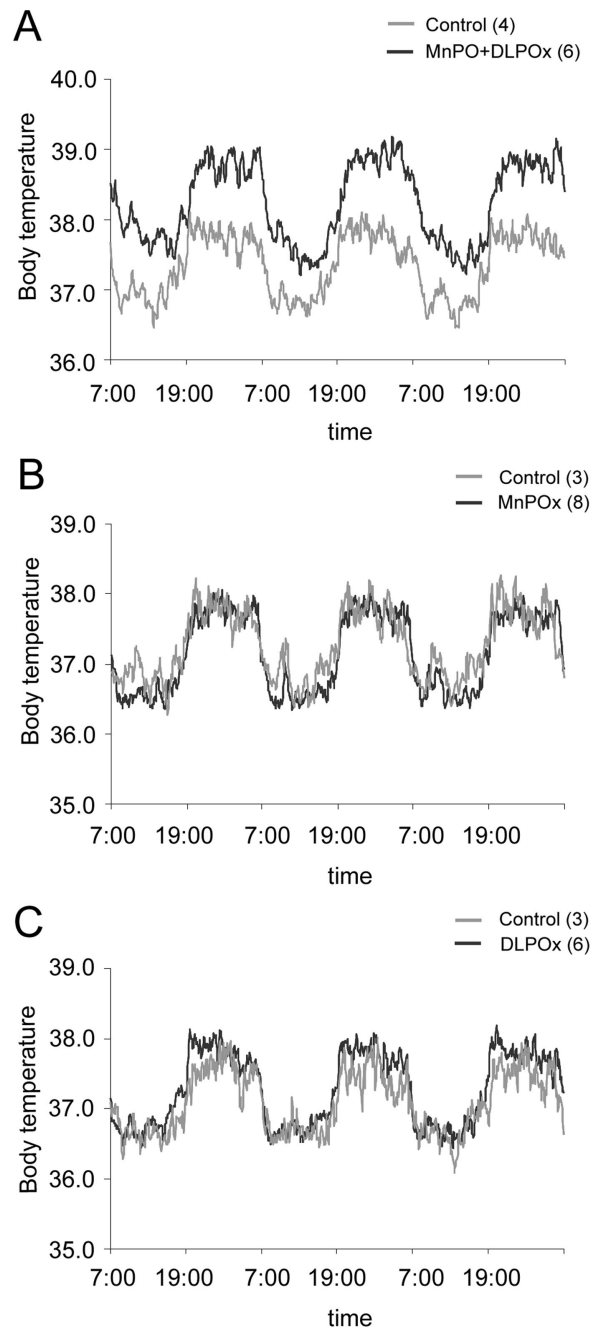

Figure 8. Mean Tb of the combined preoptic $(\mathrm{MnPO}+\mathrm{DLP})$ lesion group $(\boldsymbol{A}), \mathrm{MnPO}$ lesion group $(\boldsymbol{B})$, and DLP0 lesion group ( $\boldsymbol{C})$ over 3 consecutive days. Higher Tb was observed throughout the entire day (dark and light periods) in the combined $(\mathrm{MnPO}+\mathrm{DLPO})$ lesion group $(\boldsymbol{A})$ but not in the MnPO lesion $(\boldsymbol{B})$ or DLPO lesion $(\boldsymbol{C})$ groups. Graphs $\boldsymbol{D}, \boldsymbol{E}$, and $\boldsymbol{F}$ show the fever response after LPS injection in control animals compared with the combined (MnP0+DLP0) lesion group (D), MnP0 lesion group $(\boldsymbol{E})$, and DLP0 lesion group $(\boldsymbol{F})$. LPS was injected at time 0 . The DLP0 lesion group showed a similar pattern of temperature increase as control animals $(\boldsymbol{F})$, but neither the combined (MnPO+DLP0) nor MnPO lesion groups showed this rise in temperature ( $\boldsymbol{D}$ and $\boldsymbol{E}$, respectively). Significant differences between groups are noted by asterisks ( $p<0.05$; repeated-measures ANOVA followed by paired $t$ tests for comparisons at each time point). All values are the mean \pm SEM.

Experiment 2: Cell-specific lesions in the preoptic area: effects on baseline temperature and LPS-induced fever

Our anatomical studies indicated that both the MnPO and the DLPO send projections to the DMH/DHA area and to the RMR, but neither appeared to be activated by cold exposure, suggesting that these DMH/DHA and medullary inputs may be inhibitory. Earlier studies, reporting that that knife cuts caudal to the preoptic area or electrolytic ablation of the preoptic area caused hyperthermia in rats (Rothwell et al., 1983; Chen et al., 1998; Romanovsky et al., 2003; Almeida et al., 2006) also suggest that neurons in the preoptic area tonically inhibit hyperthermic responses. However, these ap- proaches could not distinguish the relative contribution of the $\mathrm{MnPO}$ and the DLPO to this hyperthermia. Given the evidence that the MnPO is necessary for fever-induced hyperthermia (Lazarus, 2006) and that inhibition in the region of the dorsal part of the medial preoptic region can also cause hyperthermia (Osaka, 2004) or prevent hyperthermia to cold exposure (Nakamura and Morrison, 2007), we hypothesized that both groups may play a role in this process.

We therefore placed cell-specific lesions, using ibotenic acid, to ablate either one or both of these nuclei, in an attempt to determine the source of baseline hyperthermia caused by large preoptic lesions. The mean daily $\mathrm{Tb}$ averaged over $3 \mathrm{~d}$ for each lesion group vs its matched control group is summarized in Table 1. Comparisons were done using unpaired $t$ tests.

Lesions in the first group of animals included at least $90 \%$ of the neurons in the $\mathrm{MnPO}$ and the DLPO $(n=6 ; 6$ of 12 injections produced this result). In addition to ablating both the MnPO and the DLPO, these lesions also caused variable amounts of cell loss in the medial preoptic area. In these animals, we were able to replicate the baseline hyperthermia of $\sim 1-1.5^{\circ} \mathrm{C}$ that Almeida et al. (2006) had reported with large electrolytic preoptic lesions (Fig. 8A), with the combined lesions demonstrating a significant baseline hyperthermia ( $p=$ 0.0052).

We also tested these rats for their ability to generate hyperthermia as a response to moderate stress (due to handling) and to LPS injections (Fig. 8D). Although there was a $0.5^{\circ} \mathrm{C}$ increase in $\mathrm{Tb}$ in these rats with gentle handling, we found no elevation of Tb after LPS injection; in fact, this immune challenge caused hypothermia in most animals.

We next attempted to ablate selectively either the MnPO or the DLPO. In eight rats (of 23 injected rats) that had complete MnPO lesions, but little or no damage in the DLPO, we found that baseline Tb remained normal (Fig. 8B). After LPS injection, these animals had a $0.5^{\circ} \mathrm{C}$ increase in Tb due to handling, but did not show a fever response to LPS (Fig. $8 E$ ) (the late increase in Tb after $240 \mathrm{~min}$ is due to the circadian rise in $\mathrm{Tb}$ that begins in the afternoon, anticipating wake up at 7:00 P.M.; see Fig. 8A). In 6 rats (of 10 injected rats) with complete bilateral lesions of the DLPO, but preservation of the $\mathrm{MnPO}$, we also found a normal baseline Tb (Fig. $8 C$ ). These 


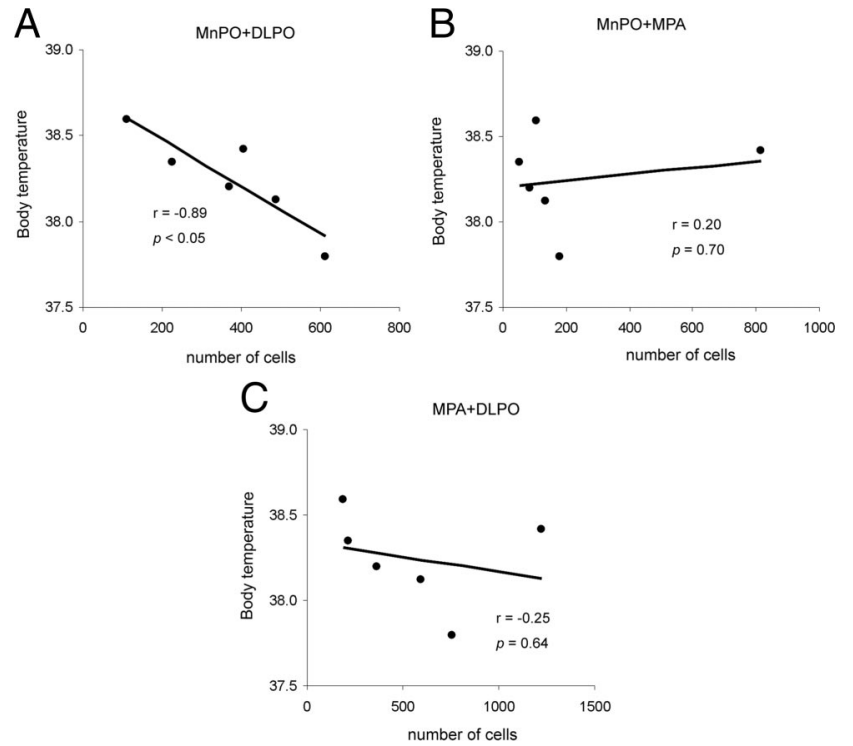

Figure 9. Elevation of Tb shows a strong negative correlation with the number of remaining neurons in the MnP0 $+\mathrm{DLPO}(\boldsymbol{A})$, but not with those in the MnP0 $+\mathrm{MPA}(\boldsymbol{B})$ or MPA $+\mathrm{DLPO}(\boldsymbol{C})$, demonstrating that only simultaneous lesions of both $\mathrm{MnPO}$ and DLPO are effective in altering baseline $\mathrm{Tb}$.

animals also had the expected $0.5^{\circ} \mathrm{C}$ increase in $\mathrm{Tb}$ caused by handling, and normal fever of $\sim 1.5^{\circ} \mathrm{C}$ after LPS injection (Fig. $8 F)$. Thus, the ablation of one or the other of these preoptic cell groups is not capable of replicating the hyperthermia seen with large preoptic lesions or knife cuts. Nevertheless, the $\mathrm{MnPO}$ appears to be necessary for mounting a fever response, while the DLPO is not.

Because the neurons in the medial preoptic area were also involved to varying extents in these injections, and earlier studies have suggested an important role for the medial preoptic area in thermoregulation, we next evaluated the contributions of these different sites to the hyperthermic response we observed by linear regression analysis. We counted the number of remaining cells in the $\mathrm{MnPO}$ (Fig. 3A, counting box 1) and DLPO (Fig. 3D, counting box 3 ), as well as in the MPA (Fig. 3D, counting box 2), across the entire set of animals with combined lesions of the MnPO and the DLPO, and then performed a Pearson correlation analysis. As shown in Figure $9 A$, the degree of hyperthermia corelated closely with the loss of neurons in the combination of the MnPO and the DLPO $(r=-0.89, p<0.05)$. Loss of neurons in the MPA apparently did not contribute to the hyperthermia, as combining the neuronal loss in the MPA with that in either the MnPO or the DLPO did not show a statistically significant correlation with hyperthermia (Fig. 9B,C).

These observations suggest that on a chronic basis either the $\mathrm{MnPO}$ or the DLPO can provide sufficient inhibition to the thermogenic system to hold it in check, and that it is the loss of the independent contributions by both of these cell groups (but not the neurons in the MPA between the two) that causes disinhibition of both the DMH/DHA and the RMR, producing hyperthermia after large preoptic lesions or knife cuts caudal to the preoptic area.

\section{Discussion}

Dual parallel pathways regulate hyperthermic responses

The present study demonstrates the existence of two parallel preoptic pathways that regulate hyperthermic responses. First, we found two separate preoptic cell groups, the MnPO and the DLPO, which send independent projections to the RMR and the DMH/DHA. As expected, the retrogradely labeled preoptic neurons do not express Fos during cold exposure, as they are believed to inhibit elevation of body temperature (Nakamura et al., 2002; Osaka, 2004). However, the DMH/DHA, which is thought to promote elevation of body temperature, shows robust Fos expression during cold challenge. Second, we found that the MnPO and the DLPO each may apparently inhibit hyperthermic responses and preserve normal $\mathrm{Tb}$ in the absence of the other. However, in the absence of both, neurons that elevate $\mathrm{Tb}$ are disinhibited and the baseline $\mathrm{Tb}$ is increased $\sim 1.5^{\circ} \mathrm{C}$, while circadian variation in $\mathrm{Tb}$ remains normal. In addition, although rats with MnPO lesions lose the ability to produce LPS-induced fever, even animals with double lesions show stress-induced hyperthermia $\left(\sim 0.5^{\circ} \mathrm{C}\right.$ increase) when handled. Thus, the stress and circadian inputs to the thermoregulatory system remain intact even after double preoptic lesions.

\section{Technical considerations}

Previous anatomical studies have not identified the DLPO as a distinct entity. The DLPO neurons are centered just lateral to the medial preoptic nucleus, overlapping the lateral edge of the medial preoptic area and the entire width of the lateral preoptic area, although they largely avoid the ventrolateral preoptic nucleus, hence our term, the DLPO. This cell group probably corresponds with the "caudolateral preoptic" site where Tanaka et al. (2009) found that injections of GABA caused an increase in tail artery sympathetic nerve activity, but injections of PGE2 did not cause hyperthermia. It is just lateral and caudal to the "dorsomedial preoptic" site (DMPO) where Osaka (2004) found that injections of GABA or muscimol caused thermogenesis. Osaka (2004) failed to obtain hyperthermic responses when the injections were placed too medially in the MnPO or too laterally in the DLPO (Osaka, 2004, see his Fig. 3). These observations would be consistent with the location of his effective injection sites just between these two thermoregulatory cell groups where they could involve both simultaneously, and our interpretation that it is necessary to disable or inhibit both the MnPO and the DLPO to permit hyperthermic responses.

Nakamura and Morrison (2007) also found that injection of bicuculline at a site that they call MPO (medial preoptic nucleus) (which appears to be the same as Osaka's DMPO) blocked the cooling-elicited activation of BAT. Because they also blocked this response by injecting muscimol into the $\mathrm{DMH} / \mathrm{DHA}$, it is likely that they were interrupting an input from the preoptic area to the DMH/DHA. In our view, the success of the injections by Nakamura and Morrison (2007), like those of Osaka, was probably due to the site that they chose being precisely between the DLPO and the MnPO, with spread of the drug into both nuclei. The preoptic neurons that project to the DMH/DHA and the RMR are arrayed on both sides of their respective injection sites, but tend to avoid the intermediate area (cf. our Fig. $3 A, B$ with Nakamura and Morrison, 2007, their Fig. 2C; Osaka, 2004, their Fig. 3). Nakamura and colleagues (Nakamura et al., 2009) hypothesized that thermogenesis after stimulating the $\mathrm{MnPO}$ required a critical relay in the MPO, but there is no known output from their MPO to thermogenic systems in either the DMH/DHA or the RMR. Instead, these projections come from the DLPO, which is laterally adjacent to their site. We hypothesize that the DLPO is the critical second preoptic site that is necessary to cause thermogenesis when the MnPO is stimulated or during cutaneous cold stimulation. 
We also found that independent populations of preoptic neurons in the MnPO and the DLPO project to the DMH/DHA vs the RMR. This finding disagrees with the observations of Nakamura et al. (2009) who used injections of CTb labeled with different fluorophores at the same two sites we used to study this pathway. They reported 10-15\% doubly labeled neurons in the MnPO and the MPO. However, they apparently only examined the most rostral part of the preoptic area, thus missing most of the DLPO group, and their "MPO" at this level consists of the ventrolateral wings of the MnPO nucleus (compare Nakamura et al., 2009, their Fig. 3, with Scammell et al., 1996, their Fig. 4). In their confocal micrographs, they show only faint double labeling of neurons (e.g., the only doubly labeled neuron shown; Nakamura et al., 2009, their Fig. 2). Although our second label was Fluorogold, which is very sensitive when used in combination with $\mathrm{CTb}$ (Lefler et al., 2008), it is possible that the conventional fluorescence microscopy in our study might have missed very light double labeling. Nevertheless, even if we accept the $10-15 \%$ overlap in the Nakamura et al. (2009) study, the projections remain 85-90\% independent, providing substantial substrate for independent regulation.

\section{Relationship of MnPO and DLPO}

A clear example of a specific physiological stimulus that differentially affects the MnPO versus the DLPO is the febrile response to PGE2. PGE2 acts on EP3 receptors in the $\mathrm{MnPO}$ (which inhibit the MnPO neurons) to cause fever, and lack of these receptors in the MnPO prevents LPS-induced fever (Lazarus et al., 2007). $\mathrm{MnPO}$ neurons containing EP3 receptors are believed to provide GABAergic inhibitory inputs to the DMH/DHA and RMR thermogenic systems (Nakamura et al., 2005). Hence, withdrawal of that inhibitory influence would produce thermogenesis. In light of this hypothesis, it is not surprising that ablation of the $\mathrm{MnPO}$ specifically causes loss of fever response.

However, the preservation of normal baseline $\mathrm{Tb}$ in rats with MnPO lesions indicates that the remaining preoptic tissue is capable of thermoregulation without the MnPO. This hypothesis runs counter to the observation by Nakamura and Morrison (2008b) that inhibition of the MnPO with glycine prevented BAT responses to skin cooling. On the other hand, neither rectal nor brain temperature fell after glycine administration to the MnPO. So even though there may be a deficit in BAT activation after MnPO lesions, other thermoregulatory systems, such as tail artery vasoconstriction, may depend upon remaining neurons, e.g., in the DLPO (Tanaka et al., 2009) to maintain Tb.

Recent studies have traced a cutaneous cold-sensitive pathway through the parabrachial nucleus to the preoptic area (Nakamura and Morrison, 2008a). The parabrachial nucleus innervates both the DLPO and MnPO (Saper and Loewy, 1980; Bester et al., 1997). We hypothesize that each of these sites can independently mediate thermoregulatory responses to cold. In this model, during fever responses the MnPO would need to suppress the counter-regulatory attempts by DLPO thermosensitive neurons to prevent the increase in $\mathrm{Tb}$. This would require an inhibitory projection from the MnPO to the DLPO, as removing either influence alone would not be sufficient to produce hyperthermia. There is an intense projection from MnPO to DLPO (Saper and Levisohn, 1983; Uschakov et al., 2007). Nakamura and Morrison (2008b) found that injection of bicuculline, a GABA-A antagonist, into their MPO (the medial edge of our DLPO) blocked BAT activation elicited from the $\mathrm{MnPO}$, supporting the concept that this projection is GABAergic.

\section{Role of the DMH/DHA vs the medullary raphe in hyperthermia}

Although there are many cold-sensitive neurons in the hypothalamus and upper brainstem, and many neuronal groups that project to the RMR, the DMH/DHA is the only one that projects to the RMR and simultaneously shows intense Fos-activation during cold challenge. Hence, these neurons are likely to play an important role in relaying thermoregulatory information from the preoptic area to systems in the brainstem that regulate elevation of Tb.

Several lines of evidence support the view that DMH/DHA neurons play an important role in BAT thermogenic responses during skin cooling, fever responses, and stress (Zaretskaia et al., 2003; Madden and Morrison, 2004; Nakamura et al., 2005; DiMicco et al., 2006; Nakamura and Morrison, 2007). However, muscimol injection into the DMH/DHA does not alter the tail artery sympathetic fiber activation during prostaglandin E2induced fever (Rathner et al., 2008). Hence, while the DMH/ DHA is a key node for regulating BAT thermogenesis responses from the $\mathrm{MnPO}$, it may play a lesser role in heat conservation responses, such as those elicited from the DLPO (Tanaka et al., 2009).

Finally, although the neurons in the DMH/DHA that project to the RMR were adjacent to and partially intermixed with the A11/A13 dopaminergic cell group, none of them were dopaminergic. In contrast, in the rostral pons, many of the CTb retrogradely labeled neurons that project to the RMR were TH-positive and, therefore, part of the A7 noradrenergic group. Pontomedullary transections or procaine injections into the mesopontine tegmentum have been found to cause hyperthermia (Rothwell et al., 1983; Shibata et al., 1996). As the A7 group and associated non-noradrenergic neurons are the only source of input to the medullary raphe from this level of the brainstem, it is possible that it may provide an important inhibitory input that holds thermogenesis in check.

\section{References}

Almeida MC, Steiner AA, Branco LG, Romanovsky AA (2006) Neural substrate of cold-seeking behavior in endotoxin shock. PLoS One 1:e1.

Bester H, Besson JM, Bernard JF (1997) Organization of efferent projections from the parabrachial area to the hypothalamus: a Phaseolus vulgarisleucoagglutinin study in the rat. J Comp Neurol 383:245-281.

Boissé L, Mouihate A, Ellis S, Pittman QJ (2004) Long-term alterations in neuroimmune responses after neonatal exposure to lipopolysaccharide. J Neurosci 24:4928-4934.

Bratincsák A, Palkovits M (2004) Activation of brain areas in rat following warm and cold ambient exposure. Neuroscience 127:385-397.

Cano G, Passerin AM, Schiltz JC, Card JP, Morrison SF, Sved AF (2003) Anatomical substrates for the central control of sympathetic outflow to interscapular adipose tissue during cold exposure. J Comp Neurol 460:303-326.

Cechetto DF, Saper CB (1988) Neurochemical organization of the hypothalamic projection to the spinal cord in the rat. J Comp Neurol 272:579-604.

Chen XM, Hosono T, Yoda T, Fukuda Y, Kanosue K (1998) Efferent projection from the preoptic area for the control of non-shivering thermogenesis in rats. J Physiol 512:883-892.

DiMicco JA, Zaretsky DV (2007) The dorsomedial hypothalamus: a new player in thermoregulation. Am J Physiol Regul Integr Comp Physiol 292:R47-R63.

DiMicco JA, Sarkar S, Zaretskaia MV, Zaretsky DV (2006) Stress-induced cardiac stimulation and fever: common hypothalamic origins and brainstem mechanisms. Auton Neurosci 126-127:106-119.

Elmquist JK, Ahima RS, Elias CF, Flier JS, Saper CB (1998) Leptin activates distinct projections from the dorsomedial and ventromedial hypothalamic nuclei. Proc Natl Acad Sci U S A 95:741-746. 
Guillery RW (2002) On counting and counting errors. J Comp Neurol 447:1-7.

Hammel HT, Hardy JD, Fusco MM (1960) Thermoregulatory responses to hypothalamic cooling in unanesthetized dogs. Am J Physiol 198:481-486.

Hayward JN, Baker MA (1968) Diuretic and thermoregulatory responses to preoptic cooling in the monkey. Am J Physiol 214:843-850.

Hermann DM, Luppi PH, Peyron C, Hinckel P, Jouvet M (1997) Afferent projections to the rat nuclei raphe magnus, raphe pallidus and reticularis gigantocellularis pars alpha demonstrated by iontophoretic application of choleratoxin (subunit b). J Chem Neuroanat 13:1-21.

Hosoya Y, Ito R, Kohno K (1987) The topographical organization of neurons in the dorsal hypothalamic area that project to the spinal cord or to the nucleus raphe pallidus in the rat. Exp Brain Res 66:500-506.

Hosoya Y, Sugiura Y, Zhang FZ, Ito R, Kohno K (1989) Direct projection from the dorsal hypothalamic area to the nucleus raphe pallidus: a study using anterograde transport with Phaseolus vulgaris leucoagglutinin in the rat. Exp Brain Res 75:40-46.

Kiyohara T, Miyata S, Nakamura T, Shido O, Nakashima T, Shibata M (1995) Differences in Fos expression in the rat brains between cold and warm ambient exposures. Brain Res Bull 38:193-201.

Lazarus M (2006) The differential role of prostaglandin E2 receptors EP3 and EP4 in regulation of fever. Mol Nutr Food Res 50:451-455.

Lazarus M, Yoshida K, Coppari R, Bass CE, Mochizuki T, Lowell BB, Saper CB (2007) EP3 prostaglandin receptors in the median preoptic nucleus are critical for fever responses. Nat Neurosci 10:1131-1133.

Lefler Y, Arzi A, Reiner K, Sukhotinsky I, Devor M (2008) Bulbospinal neurons of the rat rostromedial medulla are highly collateralized. J Comp Neurol 506:960-978.

Lu J, Sherman D, Devor M, Saper CB (2006) A putative flip-flop switch for control of REM sleep. Nature 441:589-594.

Luppi PH, Sakai K, Salvert D, Fort P, Jouvet M (1987) Peptidergic hypothalamic afferents to the cat nucleus raphe pallidus as revealed by a double immunostaining technique using unconjugated cholera toxin as a retrograde tracer. Brain Res 402:339-345.

Madden CJ, Morrison SF (2004) Excitatory amino acid receptors in the dorsomedial hypothalamus mediate prostaglandin-evoked thermogenesis in brown adipose tissue. Am J Physiol Regul Integr Comp Physiol 286:R320-R325.

McEwen GN Jr, Heath JE (1974) Thermoregulatory responses to preoptic cooling in unrestrained rabbits. Am J Physiol 227:954-957.

McKitrick DJ (2000) Expression of fos in the hypothalamus of rats exposed to warm and cold temperatures. Brain Res Bull 53:307-315.

Morrison SF (1999) RVLM and raphe differentially regulate sympathetic outflows to splanchnic and brown adipose tissue. Am J Physiol 276:R962-R973.

Morrison SF (2003) Raphe pallidus neurons mediate prostaglandin E2evoked increases in brown adipose tissue thermogenesis. Neuroscience 121:17-24.

Morrison SF (2004) Central pathways controlling brown adipose tissue thermogenesis. News Physiol Sci 19:67-74.

Nakamura K, Morrison SF (2007) Central efferent pathways mediating skin cooling-evoked sympathetic thermogenesis in brown adipose tissue. Am J Physiol Regul Integr Comp Physiol 292:R127-R136.

Nakamura K, Morrison SF (2008a) A thermosensory pathway that controls body temperature. Nat Neurosci 11:62-71.

Nakamura K, Morrison SF (2008b) Preoptic mechanism for cold-defensive responses to skin cooling. J Physiol 586:2611-2620.

Nakamura K, Matsumura K, Kaneko T, Kobayashi S, Katoh H, Negishi M (2002) The rostral raphe pallidus nucleus mediates pyrogenic transmission from the preoptic area. J Neurosci 22:4600-4610.

Nakamura Y, Nakamura K, Matsumura K, Kobayashi S, Kaneko T, Morrison SF (2005) Direct pyrogenic input from prostaglandin EP3 receptorexpressing preoptic neurons to the dorsomedial hypothalamus. Eur J Neurosci 22:3137-3146.

Nakamura Y, Nakamura K, Morrison SF (2009) Different populations of prostaglandin EP3 receptor-expressing preoptic neurons project to two fever-mediating sympathoexcitatory brain regions. Neuroscience 161:614-620.

Nason MW Jr, Mason P (2006) Medullary raphe neurons facilitate brown adipose tissue activation. J Neurosci 26:1190-1198.

Ootsuka Y, Blessing WW, Steiner AA, Romanovsky AA (2008) Fever response to intravenous prostaglandin $\mathrm{E} 2$ is mediated by the brain but does not require afferent vagal signaling. Am J Physiol Regul Integr Comp Physiol 294:R1294-R1303.

Osaka T (2004) Cold-induced thermogenesis mediated by GABA in the preoptic area of anesthetized rats. Am J Physiol Regul Integr Comp Physiol 287:R306-R313.

Paxinos G, Watson C (2005) The rat brain in stereotaxic coordinates, Ed 5. San Diego: Academic.

Rathner JA, McAllen RM (1999) Differential control of sympathetic drive to the rat tail artery and kidney by medullary premotor cell groups. Brain Res 834:196-199.

Rathner JA, Madden CJ, Morrison SF (2008) Central pathway for spontaneous and prostaglandin E2-evoked cutaneous vasoconstriction. Am J Physiol Regul Integr Comp Physiol 295:R343-R354.

Romanovsky AA, Sugimoto N, Simons CT, Hunter WS (2003) The organum vasculosum laminae terminalis in immune-to-brain febrigenic signaling: a reappraisal of lesion experiments. Am J Physiol Regul Integr Comp Physiol 285:R420-R428.

Rothwell NJ, Stock MJ, Thexton AJ (1983) Decerebration activates thermogenesis in the rat. J Physiol 342:15-22.

Saper CB, Levisohn D (1983) Afferent connections of the median preoptic nucleus in the rat: anatomical evidence for a cardiovascular integrative mechanism in the anteroventral third ventricular (AV3V) region. Brain Res 288:21-31.

Saper CB, Loewy AD (1980) Efferent connections of the parabrachial nucleus in the rat. Brain Res 197:291-317.

Saper CB, Swanson LW, Cowan WM (1976) The efferent connections of the ventromedial nucleus of the hypothalamus of the rat. J Comp Neurol 169:409-442.

Sawchenko PE, Swanson LW (1982) Immunohistochemical identification of neurons in the paraventricular nucleus of the hypothalamus that project to the medulla or to the spinal cord in the rat. J Comp Neurol 205:260-272.

Scammell TE, Elmquist JK, Griffin JD, Saper CB (1996) Ventromedial preoptic prostaglandin E2 activates fever-producing autonomic pathways. J Neurosci 16:6246-6254.

Shibata M, Iriki M, Arita J, Kiyohara T, Nakashima T, Miyata S, Matsukawa T (1996) Procaine microinjection into the lower midbrain increases brown fat and body temperatures in anesthetized rats. Brain Res 716:171-179.

Simerly RB, Swanson LW (1988) Projections of the medial preoptic nucleus: a Phaseolus vulgaris leucoagglutinin anterograde tract-tracing study in the rat. J Comp Neurol 270:209-242.

Tanaka M, McKinley MJ, McAllen RM (2009) Roles of two preoptic cell groups in tonic and febrile control of rat tail sympathetic fibers. Am J Physiol Regul Integr Comp Physiol 296:R1248-R1257.

Thompson RH, Canteras NS, Swanson LW (1996) Organization of projections from the dorsomedial nucleus of the hypothalamus: a PHA-L study in the rat. J Comp Neurol 376:143-173.

Uschakov A, Gong H, McGinty D, Szymusiak R (2007) Efferent projections from the median preoptic nucleus to sleep- and arousal-regulatory nuclei in the rat brain. Neuroscience 150:104-120.

Yoshida K, Konishi M, Nagashima K, Saper CB, Kanosue K (2005) Fos activation in hypothalamic neurons during cold or warm exposure: projections to periaqueductal gray matter. Neuroscience 133:1039-1046.

Zaretskaia MV, Zaretsky DV, DiMicco JA (2003) Role of the dorsomedial hypothalamus in thermogenesis and tachycardia caused by microinjection of prostaglandin E2 into the preoptic area in anesthetized rats. Neurosci Lett 340:1-4.

Zhang YH, Lu J, Elmquist JK, Saper CB (2000) Lipopolysaccharide activates specific populations of hypothalamic and brainstem neurons that project to the spinal cord. J Neurosci 20:6578-6586. 